\title{
The Development and Characteristics of Elementary Science Curriculum in China
}

\author{
Minghui Ma \\ Educational Science Publishing House, Beijing, China
}

\begin{abstract}
There are eight versions of science textbooks in China, and they are all written according to the curriculum standard. In recent years, science curriculum in China is developing rapidly. In the process of development, it has gradually formed its own characteristics: 1 . It is based on in-depth research. Most of their editors-in-chief and their teams have researched American or France Science textbooks, such as Science and Technology for Children (STC), Full Option Science System (FOSS), and so on. The research outcomes have been used or will be used in the revision of the textbooks; 2. It has paid more attention to science concepts and science practices. Science is both a body of knowledge that represents current understanding of natural systems and the process whereby that body of knowledge has been established and is being continually extended, refined, and revised. This is why we should pay more attention to science concepts and science practices; and 3. Science reading has played an important role in science curriculum. Science readings can help children to learn science language, realize that science is closely related to our daily life, and analyze and solve problems from the perspective of science. One of the most serious problems of science readings is the lack of educational function. In order to make the science readings play their important role in the society, we need to pay more efforts, such as we should write the science readings around core ideas, and the members of the writing teams should be diversified.
\end{abstract}

Keywords: science education, science curriculum, science textbook, learning progressions, science as practice

\section{Introduction}

In recent years, people have paid more and more attention to the science education in the world, and China is no exception. From 2001, the curriculum has changed its name from Nature to Science, the guidance document has changed its name from Syllabus to Curriculum Standard, and the students have begun to learn Science from Grade 3. It means that the science education in China is developing with world together.

\section{Overview of Science Curriculum in China}

There are eight versions of science textbooks in China, and they are all written according to the curriculum standard. The schools in different provinces can choose same or different versions, and there are no unified regulations.

\section{Revision of the Science Standard and Textbooks}

The science standard is revising now, according to the practical experiences of science education in China of more than 10 years and the science standards of other countries. When the science standard revision is

Minghui Ma, M.A., associate professor of editorship, Educational Science Publishing House. 
completed, the textbooks will revise right now according to the new standard and the related research outcomes.

\section{Example of One Version of Science Textbook}

The science textbook published by Educational Science Publishing House (ESPH) is the best textbook in China, and its market share is the largest. So, we will take it as an example.

There is one textbook every semester, so there are eight textbooks totally, from Grade 3 to Grade 6. In every textbook, there are four units (see Table 1). In every unit, there are seven or eight lessons (see Table 2). These units cover four fields: physical science, life science, earth and space science, and design and technology.

Table 1

Units in Each Textbook

\begin{tabular}{|c|c|c|c|}
\hline Grade & Unit & Grade & Unit \\
\hline \multirow{4}{*}{$3-1$} & Plants & \multirow{4}{*}{$3-2$} & Development of Plants \\
\hline & Animals & & Life Circle of Animals \\
\hline & Materials Around Us & & Change of Temperature and Water \\
\hline & Water and Air & & Magnets \\
\hline \multirow{4}{*}{$4-1$} & Solution & \multirow{4}{*}{$4-2$} & Electricity \\
\hline & Sound & & New Life \\
\hline & Weather & & Food \\
\hline & Our Body & & Rocks and Minerals \\
\hline \multirow{4}{*}{$5-1$} & Motion and Force & \multirow{4}{*}{$5-2$} & Sinking and Floating \\
\hline & Light & & Measurement of Time \\
\hline & Organisms and Their Environments & & Heat \\
\hline & The Earth's Surface and Its Change & & The Earth's Motion \\
\hline \multirow{4}{*}{$6-1$} & Shapes and Structures & \multirow{4}{*}{$6-2$} & Microworlds \\
\hline & Tools and Machines & & Change of Materials \\
\hline & Energy & & The Universe \\
\hline & Biological Diversity & & Our Environments and Us \\
\hline
\end{tabular}

Teble 2

Lessons in Each Unit of Textbook 3-1

\begin{tabular}{|c|c|c|c|}
\hline Unit & Lesson & Unit & Lesson \\
\hline \multirow{7}{*}{ Plants } & 1. What can I See & \multirow{7}{*}{ Animals } & 1. Search for the Small Animals \\
\hline & 2. Trees in the Campus & & 2. Snails (1) \\
\hline & 3. Trees and Grass & & 3. Snails (2) \\
\hline & 4. Aquatic Plants & & 4. Earthworms \\
\hline & 5. Leaves & & 5. Ants \\
\hline & 6. What's Happened to the Trees & & 6. Goldfishes \\
\hline & 7. What are the Same Characteristics of Plants & & 7. What are the Same Characteristics of Animals \\
\hline \multirow{7}{*}{$\begin{array}{l}\text { Materials } \\
\text { Around Us }\end{array}$} & 1. Materials Around Us & \multirow{7}{*}{$\begin{array}{l}\text { Water and } \\
\text { Air }\end{array}$} & 1. Water \\
\hline & 2. Which Kind of Materials is Hard & & 2. Comparison of Water and Oil \\
\hline & 3. Comparison of Flexibility & & 3. Who flows Faster \\
\hline & 4. Can They Absorb Water & & 4. Comparison of the Amount of Water \\
\hline & 5. Sinking and Floating in the Water & & 5. Air Around Us \\
\hline & 6. Brick, Tile, Pottery and Porcelain & & 6. Does Air Occupy Space \\
\hline & 7. Material Classification & & 7. Does Air Have Weight \\
\hline
\end{tabular}




\section{Characteristics of Science Curriculum in China}

With the development of science education theory—learning science theory, constructivism theory, and cognitive theory, science curriculum in China is developing rapidly. In the process of development, it has gradually formed its own characteristics.

\section{Based on In-Depth Research}

There are eight versions of Science textbooks in China as the author has mentioned above. Most of their editors-in-chief and their teams have researched American or France Science textbooks, such as Science and Technology for Children (STC), Full Option Science System (FOSS), and so on. The research outcomes have been used or will be used in the revision of the textbooks.

The development and revision of ESPH Science textbooks are based on STC research ${ }^{1}$. STC is a set of science curriculum (K-8) developed by National Science Resources Center (NSRC), which is now renamed Smithsonian Science Education Center (SSEC). It is listed as one of the typical inquiry basing science curricula on a global scale by International Academy Panel (IAP).

Overview of the STC curriculum experiment. From 2006, 10 schools from eight provinces and cities of China conducted the STC curriculum experiment under the guidance of ESPH and Elementary Science Education Research Center of China National Institute for Educational Research (CNIER), which is now renamed National Institute of Education Science (NIES). The provinces and cities are Beijing, Tianjin, Hubei, Chongqing, Guangdong, Jiangsu, Zhejiang, and Liaoning. Seven hundred and forty-one students and 33 teachers from 20 classes have participated in the experiment (Yu, 2013). In these years, we have conducted complete experimental demonstration about STC curriculum in China, observed speeches and behaviors of elementary students with the intervention of STC curriculum, recorded student reactions to the principles and strategies of Inquiry Based Science Education (IBSE), and discussed what we should learn to promote Chinese science education reform.

Methods and process. Every teacher in the program participates in the training before semesters begin. Two teachers present when the class begins. One is in charge of teaching, the other observing and collecting the factual information. The information includes the whole process of teaching recorded by the camera, recording sheets for class, recording sheets for every student, students' science diaries, teachers' teaching diaries, and a variety of assessment information.

On the basis of the collected information, within the framework of the experimental research, we have done analytical reasoning using the existing theories, received the relevant evidences about students' development, and recognized the role of curriculum in the students' development.

Outcomes and conclusions. We have found that all of the STC curriculum goals can be achieved in the classes. Usually, students describe their experiences and feelings about the section learning using the words, such as interesting, excited, a feeling of success, and so on. On the level of conceptual understanding, the students show the development of hierarchy, multidimensional connecting, logical, and reflective characteristics. As to the science reasoning and argumentation, the students show obvious periodic characteristics from junior to senior. We have observed that children's critical awareness is developed as the improvement of inquiry proficiency.

\footnotetext{
1 Sources: The Poster in the Inter Academy Partnership Science Education Programme (IAP SEP) Biennial Conference 2014 of Ms. Yu Bo (the editor-in-chief of ESPH science textbooks).
} 
The most important enlightens for Chinese science educators, including science teachers, is that the design and implementation of the science curriculum must be based on a deep understanding of nature of science. We should pay more attention to children's learning potential and learning ability, and care and support their development requests.

At present, four elementary schools in Beijing, Wuhan, Wenzhou, and Shenzhen have started the second round of the STC curriculum experiment in order to further deepen the research.

\section{Paying More Attention to Science Concepts and Science Practices}

Science is both a body of knowledge that represents current understanding of natural systems and the process whereby that body of knowledge has been established and is being continually extended, refined, and revised. Both elements are essential. One cannot make progress in science without an understanding of both. That is why we should pay more attention to science concepts and science practices.

Organizing science curriculum around core concepts. In order to develop a deep understanding of scientific explanations of the natural world, students need sustained opportunities to work with and build the concepts that support these explanations and to understand the connections between concepts. While students are continually introduced to new concepts, unless those concepts connect to other related ideas, they will not build conceptual understanding in a meaningful way.

Theories about core concepts and learning progression. Research strongly suggests that a more effective approach to science learning and teaching is to teach and build core concepts of science over a period of years, rather than weeks or months. These core concepts offer an organizational structure for the learning of new facts, practices, and explanations, and they prepare students for deeper levels of scientific investigation and understanding in high school, college, and beyond (Michaels, Shouse, \& Schweingruber, 2007).

The core concepts are science ideas that have been well tested and validated and are central to the disciplines. Examples of core concepts in science are the atomic-molecular theory of matter, evolutionary theory, cell theory, and Newtonian laws of force and motion —all of which are considered foundational ideas in science. Each integrates many different findings and is the source of coherence for many key concepts, principles, and even other theories in the discipline. Each guides new research and can be understood in progressively more complicated ways. Each enables creative links to be made between disciplines (Michaels, Shouse, \& Schweingruber, 2007).

Research indicates that one of the best ways for students to learn the core concepts of science is to learn successively more sophisticated ways of thinking about these ideas over multiple years. These are known as "learning progressions.” Learning progressions can extend all the way from preschool to twelfth grade and beyond-indeed, people can continue learning about core science concepts in their whole lives. If mastery of a core concept in science is the ultimate educational destination, learning progressions are the routes that can be taken to reach that destination (Michaels, Shouse, \& Schweingruber, 2007).

Example of core concepts and learning progression. Core concepts may integrate many different findings and are the source of coherence for many key concepts, principles, and even other theories in the discipline. Every core concept can guide new research and can be understood in progressively more complicated ways. And every core concept enables creative links to be made between disciplines.

For example, we take conservation of energy and energy transfer as one of the core concepts. Because it is important in Physics, Chemistry, and Biology. Physicists can explain the transformation of different kinds of 
energy using it, such as mechanical energy, chemical energy, internal energy, electric energy, and so forth. Chemists can apply it to describe and explain the energy change in the chemical reactions. Biologists often explain the interaction between the organisms and environments, according to it.

Based on the relative research, we use the core concept "conservation of energy and energy transfer" to build the learning progression.

By the end of Grade 3, students should know that magnets can exert forces on other magnets or magnetizable materials, thereby transferring energy (e.g., in the form of motion) even when the objects are not touching. Plants capture energy from sunlight, which can later be used as fuel or food.

By the end of Grade 4, students should know that sunlight warms Earth's surface, and that energy can be transferred from place to place by electric currents, which can then be used locally to produce motion, sound, heat, or light.

By the end of Grade 5, students should know that when objects collide, energy can be transferred from one object to another, thereby changing their motion, and that light also transfers energy from place to place (for example, energy radiated from the sun is transferred to the earth by light).

By the end of Grade 6, students should know that energy is present whenever there are moving objects, sound, light, or heat, and that energy can be converted from on form to another.

Teaching science as practice. The new period of the development of science education is "science as practice” (Resier, 2007). People use the term "practices," instead of a term such as "skills," to emphasize that engaging in scientific investigation requires not only skill, but also knowledge that is specific to each practice (Committee on a Conceptual Framework for the New K-12 Science Education Standards \& National Research Council, 2011).

Features and kinds of science practices. Social interaction, use of language of science, use of scientific representations and tools are three features of science as practice. There are eight practices in the science classrooms: asking questions; developing and using models; planning and carrying out investigations; analyzing and interpreting data; using mathematics, information and computer technology, and computing thinking; constructing explanations; engaging in argument from evidence; and obtaining, evaluating, and communicating information (Next Generation Science Standards Lead States, 2013). Science curriculum should support students engaging in science as practice, from scientific process, social interaction, conceptual models, articulation, and reflection.

Guiding principles and examples of science practices. Students in Grades 3-6 should engage in all eight practices over each grade band. The eight practices are not separate, but intentionally overlap and interconnect. Practices grow in complexity and sophistication across the grades. It means that each of the eight practices has its own progression from Grade 3 to Grade 6.

We can take the practice of "planning and carrying out investigations" as an example.

In Grade 3, students should learn to plan and conduct an investigation in collaboration with peers under a teacher's guidance, and produce data to serve as the basis for evidence to answer a question.

In Grade 4, students should learn to make observations and measurements to collect data that can be used to make comparisons, and evaluate different ways of observing and measuring a phenomenon to determine which way can answer a question.

In Grade 5, students should learn to plan and conduct an investigation collaboratively to produce data to serve as the basis for evidence, using fair tests in which variables are controlled and the number of trials is 
considered, and make predictions about what would happen if a variable changes.

In Grade 6, students should learn to plan and conduct an investigation individually and collaboratively to produce data to serve as the basis for evidence that meet the goals of the investigation, and evaluate the accuracy of various methods for collecting data.

\section{Science Reading has Played an Important Role in Science Curriculum}

Researchers have demonstrated the centrality of reading to the practice of science, showing that, on average, scientists read for 553 hours per year or $23 \%$ of total work time. Scientists were found to consider reading as essential to their work and as their primary source of creative stimulation (Committee on a Conceptual Framework for the New K-12 Science Education Standards \& National Research Council, 2011).

The role of science reading. There are four strands of science learning: (a) Know, use, and interpret scientific explanations of the natural world; (b) Generate and evaluate scientific evidence and explanations; (c) Understand the nature and development of scientific knowledge; and (d) Participate productively in scientific practices and discourse (Reiser, 2007). Science reading is one of the most important parts of science education and science curriculum.

Science reading can help children to learn science language. In science readings, words often are given very specific meanings that are different from and often more restrictive than their everyday usage. For example, usually, a scientific "theory" is an explanation that has undergone significant testing (e.g., theory of electromagnetism). But in everyday language, it is often indistinguishable in its use from "guess," "conjecture," "speculation," "prediction," or even "belief” (e.g., "my theory is that it will rain tomorrow"). Through the practice of science reading, children can learn and use science language correctly, and develop the skill and ability to construct meaning from science readings.

Science reading can help children to realize that science is closely related to our daily life. Science is closely related to our daily life. For example, many scientists and engineers make daily products using the corresponding scientific principles. For some reason, there are not so many contents of relationship between science and daily life in science textbooks. And sometimes, some teachers teach these contents in few words. Therefore, many children do not understand the close relation between science and daily life, and do not understand that the most phenomena of life can be explaining by science.

Science readings can provide a lot of resources that can help children to understand the close relation between science and daily life. Through science reading, children can actually understand that science is not as simple as hands-on in classrooms, the knowledge, inquiry methods, and the ideas all can be used in our daily life.

Science reading can help children to learn to analyze and solve problems from the perspective of science (Ma, 2011). In our science class, teachers often teach some historical contents. Undoubtedly, it plays an important role in understanding the nature of science for children. But most of the historical contents in science textbooks and classes are history of science. It seems that only the history of science can be connected with science. Consequently, many children apply the scientific thinking to science learning and science problems solving only. When they meet the daily or historical events, they will be at a loss.

Science readings will make up for this drawback. Some famous events (e.g., the sinking of Titanic) can be analyzed from the perspective of science in science readings. For the same thing, different people with different perspectives will see the different things. With the help of science readings, children can think of and solve the problems with a scientific way of thinking. 
The current problems of the science readings. As mentioned above, science readings should be bearing the important function of education. But as the carrier of science reading, many of the science readings can not make us satisfied. One of the most serious problems of science readings is the lack of educational function.

Broad but not comprehensive. The current science readings are very rich in content, but it is only broad, not comprehensive. Most of the science readings can not explain a concept deeply, so it makes the children unable to construct the comprehensive understanding. At the same time, it is no benefit to construct the Big Ideas.

Loosely connected with our daily life. The current science readings seem like the Children's Encyclopedia rather than science readings. They can provide a lot of knowledge to children, but they ignore the connection between science and our daily life.

Of course, some of science readings strive to be connected with our daily life, but they do not get the effect of the ideal. The science readings, from content to language, all need to be connected with our daily life. It should be make the children know that science is in our daily life.

Lack of consciousness of tool. Science is a tool to know and understand the world. But now, not only children, but also adults are lack of the consciousness of tool. They cannot analyze the events that happened in our life from the angle of science. Science readings should teach children to use this tool well. But in fact, some science readings cannot bear the responsibility. They are so shallow that children can obtain some fragmented information only through them, and they cannot construct Big Ideas, not to mention the consciousness of tool.

Solutions. In order to make the science readings play their important role in the society, we need to pay more efforts. From the angle of writing a science reading, we need to write according to a core idea, from multidimensional and multiple perspectives. From the angle of a writing team, we need the cooperation of scientists, science educators, children's literature writers, psychologists, and science writers.

Writing around core ideas. The content of a science reading should be refining and in order, and at the same time, it should be pointed to the core idea. The content choice and content arrangement should be serving to the core ideas.

For example, Floating and Sinking (The National Academy of Sciences and the Smithsonian Institution, 2004) is a very well science reading. This book grasps the core idea "floating and sinking" closely, and connects the concept floating and sinking with history, society, and nature. In this book, there are different kinds of boats in different historical periods, some model basins and divers and submariners in the contemporary, and kinds of plants and animals in the sea, etc.. Thus, it breaks the boundaries of the life science and the physical science, and combines the people and the events in various periods, through historical events and science stories, graphs and satellite photos, copies of the patents and structural anatomy.

Members of the writing teams should be diversified. In terms of writing of science readings, we should break the framework of writing by authors who are good at science stories writing only. We should seek and form writing teams that are diversified. For example, a writing team can be made of a science consulting team and a cooperative team. The science consulting team can be made of some scientists who are in charge of putting forward the proposal about the contents at first and ensuring the correctness of the content at last. The cooperative team can be made of an editor-in-chief, a publisher, a literature researcher, and an author, etc.. They complete a science reading together through cooperation. 


\section{Looking Forward to the Future}

In the future, the elementary science curriculum will be developed as a three-dimensional curriculum. The first dimension is the printed curriculum. The textbooks, the activity books, science readings, and teacher guider book are included. The second dimension is the inquiry curriculum. The kits are included. The third dimension is the digital curriculum.

\section{References}

Committee on a Conceptual Framework for the New K-12 Science Education Standards, \& National Research Council. (2011). A framework for K-12 science education: Practices, crosscutting concepts, and core ideas. Washington, D.C.: National Academies Press.

Committee on a Conceptual Framework for the New K-12 Science Education Standards, \& National Research Council. (July 20, 2011). A framework for K-12 science education: Practices, crosscutting concepts, and core ideas (Preliminary Public Draft) [EB/OL]. Retrieved September 15, 2011, from http://www.nap.edu/catalog.php?record_id=13165

Ma, M. H. (2011). The lack of educational function of Chinese popular science books and solutions to this problem. View on Publishing, 4(60).

Michaels, S., Shouse, A. W., \& Schweingruber, H. A. (2007). Ready, set, science!: Putting research to work in K-8 science classrooms. Washington, D.C.: National Academies Press.

Next Generation Science Standards Lead States. (2013). Next generation science standards: For states, by states (2nd ed., p. 48). Washington, D.C.: The National Academies Press.

Reiser, B. (2007). Taking science to school: Learning and teaching science in grades K-8. Committee on Science Learning, Kindergarten through 8th grade: National Research Council, Board on Science Education, Division of Behavioral and Social Sciences and Education. R. A. Duschl, H. A. Schweingruber, \& A. W. Shouse (Eds.). Washington, D.C.: National Academy Press.

The National Academy of Sciences and the Smithsonian Institution. (2004). Floating and sinking. Washington, D.C.: National Science Resources Center.

Yu, B. (January, 2013). STC curriculum experiment-curriculum research based on the practices. Beijing: Educational Science Publishing House. 